\title{
Review of: "Site-specific Equivalent Linear Response Analysis and Liquefaction Hazard Evaluation of Hawassa Town, Main Ethiopian Rift"
}

Chandana $\mathrm{N}$

Potential competing interests: The author(s) declared that no potential competing interests exist.

\section{Abstract}

Abbreviate SPT, NEHRP, PGA, SA

Line "The FS was less than unity for the typical one site and greater than unity for the other typical 4 sites" needs more clarity.

A line on Typical sites will give more clarity about abstract

Introduction

Check the line "The potential of liquefaction of the study site in earthquake prone area is evaluated using factory of safety (FS), cyclic stress ratio (CSR) and cyclic resistance ratio (CSR)".

More clarity on the study conducted is needed in Introduction.

Methodology and results

The current version of paper is more of information passing, than critical analysis and linkages of is effect. Paper needs to be critically analyzed and reporting of things need to be minimized.

The paper is based on the " evaluating the local site effects and liquefaction hazard potential in Hawassa town in Southern Ethiopia". The paper should give suggestions/recommendation to solve the liquefaction issues based on the results obtained in this study. I think that the journal readers would like to have framework on how to determine the occurrence of liquefaction for the earthquake.

General comments

1. Paper is too lengthy

2. Paper requires crisp writing

3. Emphasis should be given on critical writing 